\title{
SBIR Phase I Report
}

\author{
Project Title: \\ "Monitoring Volatile Organic Tank Waste Using Cermet \\ Microsensors
}

Project Number:

DOE No.DE-FG02-04ER83901

\author{
Submitted on: \\ March 13, 2006* \\ *(Originally submitted as part of a Phase II Proposal, April, 2005)
}

Submitted by:

Edward G. Gatliff, Ph.D.,President

Applied Natural Sciences, Inc.

4129 Tonya Trail

Hamilton, Ohio 45011 


\section{Table of Contents}

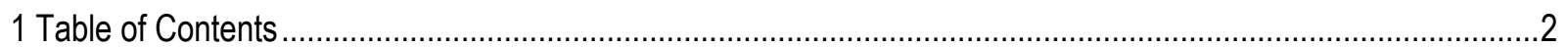

2 Identification and Significance of the Problem or Opportunity, and Technical Approach ..................................... 3

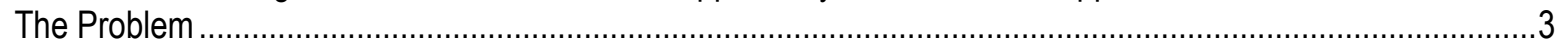

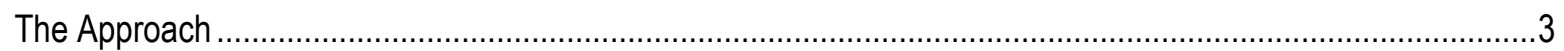

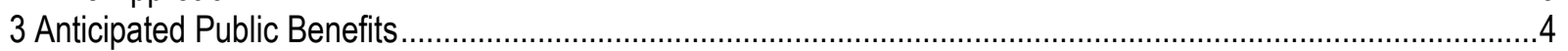

The Potential for Commercial Application ..................................................................................... 4

4 Degree to which Phase I has Demonstrated Technical Feasability ............................................................. 5

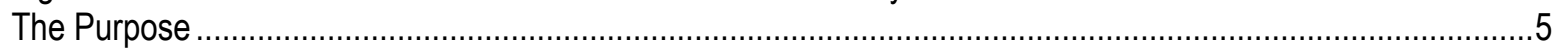

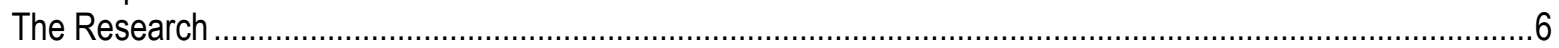

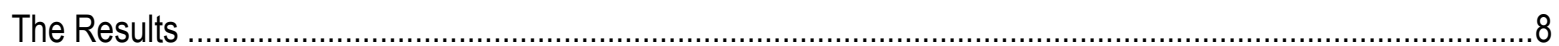

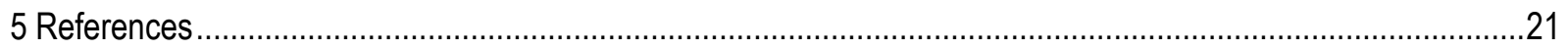

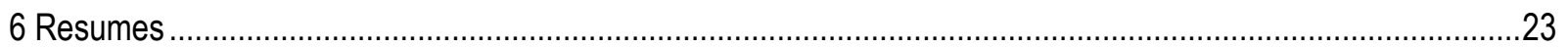

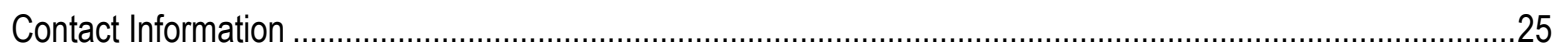

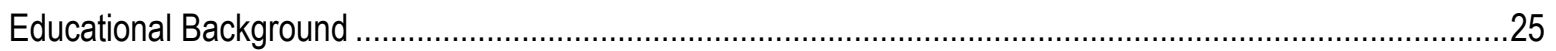

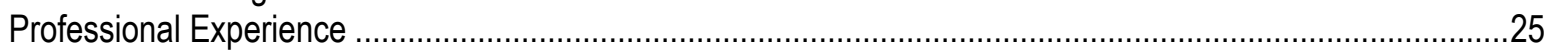

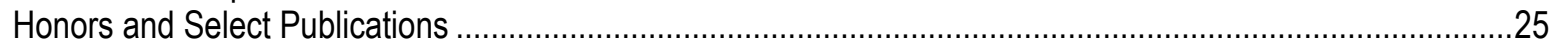




\section{Identification and Significance of the Problem or Opportunity, and Technical Approach}

\section{The Problem}

Advances in chemistry and chemical engineering in the past fifty years have produced numerous types of organic compounds for various applications. The concomitant problem with the production of these compounds is the storage, use, and disposal of them. Oftentimes, a synthesized organic may have a finite lifetime before it becomes unstable and degrades into daughter products, may be housed in a container that is not tracked properly and the contents become unknown, or may be mixed with other constituents or waste which may induce changes in the chemistry of the stored organic. In any scenario, determining the constituents and/or purity of the contents of a storage tank becomes an expensive and sometimes dangerous sampling and analytical problem. In the marketplace today, very few technologies exist that can quickly, accurately, and reliably determine both the type of organic constituent in a tank and the concentration of the organic. Current contaminant sensors in the research arena rely on determining concentrations in the aqueous phase or in the gas phase and include fiber optic technology [Barnoski, Rogers], spectroelectrochemical sensing [Heineman], surface acoustic wave sensors [Grate], surface plasmon resonance sensors [Kano], and photocatalytic sensors [Skubal]. Common, commercially available technologies include rapid gas chromatography/ mass spectrometry (GC/MS) and Dräger tubes. However, these devices cannot remain in the tank and be used at a later date; they oftentimes can only detect the presence or absence of a compound and cannot provide concentration data. In addition, they oftentimes are not very portable, and many times can only detect one compound.

\section{The Approach}

ANS and Argonne National Laboratory have been Cooperative Research and Development (CRADA) partners since 1995 and have been funded previously by DOE, including a Phase I and II SBIR Carbon Sequestration study. For the work proposed in this SBIR project, Argonne's capabilities will be utilized to develop a microsensor that will be used for tank waste monitoring. The microsensor will be small, portable, inexpensive, rugged, and can be used to determine the type and concentration of an organic constituent in the headspace of a tank. Provided the vapor pressure of an organic is sufficient to warrant its fugacity into the headspace, the concentration of an organic in a closed container (such as a chemical storage tank) can be determined in both containers of concentrated organics or in tanks containing dilute solutions of organics. For neutral organic compounds in dilute solutions, the compound will partition between the aqueous phase and the gas phase by Henry's Law Constant, $\mathrm{K}_{\mathrm{H}},\left(\mathrm{K}_{\mathrm{H}}=\mathrm{P}_{\mathrm{i}} / \mathrm{C}_{\mathrm{w}}\right.$ where $\mathrm{P}_{\mathrm{i}}=$ the partial pressure of the organic and $\mathrm{C}_{\mathrm{w}}$ is the molar concentration in an aqueous phase) [Schwarzenbach]. Once the concentration of the organic in the headspace is determined, the concentration of organic in the aqueous phase can be easily calculated. For solutions containing concentrated and relatively pure organic compounds, the vapor pressure of the organic is known at a given temperature, and the concentration measured in the headspace of the vessel by the sensor will provide a good estimation of the purity of the solvent in the tank. 
The sensors will require low power consumption (on the order of tens of milliwatts as shown in past related research) and will operate in near-real time. This collaboration with ANL will allow us to test and evaluate the latest technology in monitoring and has direct applications to our current and future consulting objectives.

\section{Anticipated Public Benefits}

The benefits from this project are numerous. Sensors that have the capability to detect multiple gases over orders of magnitude in concentration in near-real time simply do not exist in today's marketplace. The research proposed here investigates a technology that is in the direction of achieving this goal.

This technology will also provide an alternative to high cost tank sampling and analytical methods. The advantage of the proposed technology is that it is inexpensive, rugged, provides results in near-real time, and can be left in situ for future sampling efforts. From a social perspective, it can reduce human effort and the human health risks that can be associated with sampling unknown or unstable tank waste. Due to the widespread storage and use of organics in process industries, defense applications, and cleanup efforts, the market for commercialization of such a product appears strong. This product will be marketed to private industries and federal agencies for use on a wide variety of remediation, cleanup, and monitoring applications.

The product will consist of an array of sensors, a voltammatry board to drive the sensor, a PLC or comparable interface with direct-link or mobile communication system to process and store the data.

\section{The Potential for Commercial Application}

\section{Research to Enhance Commercial Application}

While the primary focus of this research is on the development of the sensor for use with tank systems, in-situ environmental monitoring may offer an opportunity to broaden the commercial viability. As with the tank sensors, the opportunity to create a fixed in-situ sensor that can provide economical temporal data on environmental contaminants would be highly desirable and make the product even more commercially viable. Since gases studied for the tank environment are equally applicable to many in-situ environmental situations, it will be a relatively straightforward effort to employ the same sensors in below ground applications.

The focus of this research will be on utilizing these catalytically enhanced microsensors that will be protected by gas-permeable membranes in a subterranean environment. These sensors will be designed to remain in subterranean remediation areas and be available to detect concentrations of the tank-studied organics compounds. Our strategy will be to use a suite of sensors (including sensor replicates) in contaminated areas of the soil vadose zone to determine gradients and changes in contaminant concentrations and evaluate the effectiveness of remediation efforts on a subsurface basis.

We propose to utilize these sensors at several locations including DOE sites. The DOE site is at Argonne National Laboratory where a phytoremediation system has been employed to remediate 
TCE and PCE contaminants in the soil and groundwater. Another site has benzene and ethylbenzene contaminants in the soil and groundwater. Several other sites are available and will be selected on the basis of site conditions and other issues.

As practitioners in the field of environmental consulting and remediation, ANS has recognized the need for a more effective and efficient approach to monitoring remediation sites, particularly for subsoil environments and tank waste. Improvements to contaminant monitoring would enhance not only ANS' current consulting abilities but also provide a promising licensing opportunity to expand the offering of this technology to other environmental remediation and monitoring companies. Our experience with developing, patenting, and applying new technologies to the environmental consulting community makes us uniquely qualified to commercialize such a product.

Tank monitoring, especially for mixed waste environments has proven to be a costly and risky proposition and often yields less than satisfactory results. Correspondingly, soil monitoring, regardless of what remediation effort is implemented, has historically relied upon laborintensive, expensive sampling and analytical procedures. In the cleanup of federal facilities, public funds are used to achieve these cleanup efforts. A significant portion of the funds are used to assess if remediation efforts are working, and if cleanup endpoints have been met.

The proposed technology is unique, as it can be applied to waste and mixed-waste storage tanks as well as numerous types of soil and groundwater remediation strategies, including biological, phytoremediation, chemical, and natural attenuation efforts. The success of the sensor technology can greatly reduce the amounts of public funds spent on environmental monitoring and cleanup. The technology can be used to monitor tank and tank farm conditions as well as environmental cleanup progress in situ, without the disruption of soils and loss of contaminants that typically accompany sample collection, packaging, shipping, and analysis. In addition, it can reduce human effort and the human health risks that can be associated with monitoring tanks and the disruption of contaminated soils (from contaminated dusts, vapors, etc.) during sample collection procedures.

\section{Degree to which Phase I has Demonstrated Technical Feasability}

\section{The Purpose}

The objective of the Phase I research was to develop sensors, to test them with various compounds, to determine their reactivity and responsiveness to specific compounds, and to assess their usefulness in determining concentrations of specific gases commonly found in the headspace of underground storage tanks.

Specific, truncated objectives were as follows:

Task 1: (ANL) Develop cermet sensors tailored for detecting and discriminating several organic compounds including TCE, PCE, acetone, and acetophenone (provided the gas supplier can prepare the desired standard concentrations and stabilize them). 
Task 2: Test the cermet sensors with standard gas concentrations. 1000 ppmv stock standards of TCE, PCE, acetone, and acetophenone will be tested with the sensors.

Task 3: 1000 ppmv stock standards of TCE, PCE, acetone, and acetophenone will be diluted to 100 ppmv and 10 ppmv. The background air (containing less than $10 \mathrm{ppm}$ of water) will be used to dilute the stock gases. The diluted standards will be tested with the sensors.

Task 4: Mixtures of two or more compounds (1000 ppmv nominal concentration) of TCE, PCE, acetone, and acetophenone will be analyzed. The test matrix will include the following:

\begin{tabular}{|c|c|c|c|c|c|c|c|c|c|c|c|c|c|c|c|}
\hline compound & \multicolumn{15}{|c|}{ test matrix, $x=1000 \mathrm{ppmv}$ constituent in test chamber } \\
\hline TCE & $\mathrm{x}$ & & & & $\mathrm{x}$ & $\mathrm{x}$ & $\mathrm{x}$ & & & & $\mathrm{x}$ & $\mathrm{X}$ & $\mathrm{x}$ & & $\mathrm{x}$ \\
\hline PCE & & $\mathrm{X}$ & & & $\mathrm{X}$ & & & $\mathrm{X}$ & $\mathrm{X}$ & & $\mathrm{X}$ & $\mathrm{X}$ & & $\mathrm{x}$ & $\mathrm{X}$ \\
\hline acetone & & & $\mathrm{x}$ & & & $\mathrm{X}$ & & $\mathrm{x}$ & & $\mathrm{x}$ & $\mathrm{x}$ & & $\mathrm{x}$ & $\mathrm{x}$ & $\mathrm{x}$ \\
\hline acetophenone & & & & 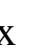 & & & $\mathrm{x}$ & & $\mathrm{x}$ & $\mathrm{x}$ & & $\mathrm{X}$ & $\mathrm{x}$ & $\mathrm{x}$ & $\mathrm{x}$ \\
\hline
\end{tabular}

Task 5: A test matrix will be established in a sealed tank. Water in the tank will be spiked with TCE, PCE, acetone, acetophenone and/or combinations of the compounds. The sensors will be inserted into the headspace of the tank and sealed so that they remain in the tank. Electrodes from the sensor will remain outside of the tank so that they can be connected to the data acquisition system for periodic sampling. Voltammograms will be collected.

Task 6. The report of these activities is discussed below.

\section{The Research}

Two types of cermet sensors were fabricated for this work: yttria stabilized zirconia cermet (ceramic-metallic) sensors and tungsten bismuth oxide cermet sensors. Sensors were prepared by screening pastes made by Heraeus-Cermalloy ${ }^{\mathrm{TM}}$ using an industrial quality Preseco ${ }^{\mathrm{TM}}$ thickfilm screen printer. Nickel oxide, platinum, and tungsten bismuth oxide and/or yttria stabilized zirconia patterns were laid onto $5.08 \mathrm{~cm}$ by $5.08 \mathrm{~cm}$ Coors ${ }^{\mathrm{TM}}$ aluminum oxide substrates which were laser perforated into $1.27 \mathrm{~cm}$ by $1.27 \mathrm{~cm}$ sections. The deposited films were successively fired to the temperature ranges in Table 1 using a Lindberg ${ }^{\mathrm{TM}}$ Super Kanthal furnace. $\mathrm{The}^{\mathrm{Al}} \mathrm{O}_{2} \mathrm{O}_{3}$ plates were separated into sixteen individual sensors after all layers were deposited and fired individually.

Table 1. Firing temperatures of deposited films.

\begin{tabular}{|l|l|}
\hline Component & Temperature, ${ }^{\circ} \mathrm{C}$ \\
\hline $\mathrm{NiO}$ & 1350 \\
\hline $\mathrm{Pt}$ & $1150-1350$ \\
\hline YSZ & $1150-1350$ \\
\hline WBO & 850 \\
\hline
\end{tabular}




\begin{tabular}{|l|l|}
\hline $\mathrm{Pt}$ & 850 \\
\hline
\end{tabular}

Figure 1 shows a cross section of an YSZ sensor as imaged by scanning electron microscopy (SEM).

Figure 1. SEM image of the cross section of a YSZ sensor.

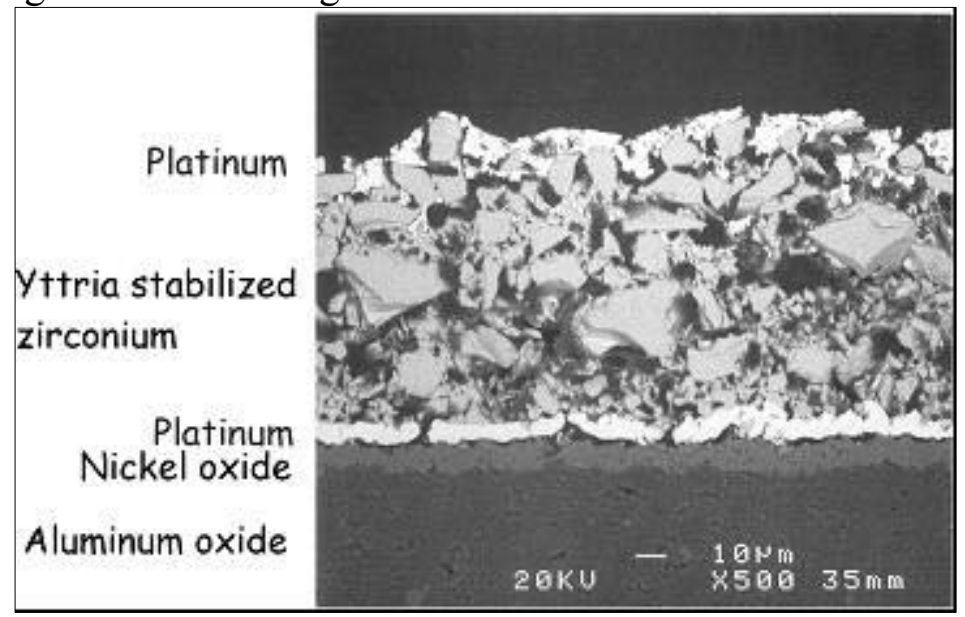

Lead frames were soldered on to each sensor with a high temperature $\left(290^{\circ} \mathrm{C}\right)$ silver-loaded solder. Sensors were initially tested for their response to zero chromatographic air (AGA). Sensors responses were collected; responses of sensors that were within 5\% of each other were used for subsequent tests. Figure 2 shows the sensor, the sensor in a sampling enclosure, and a complete voltammetric test system.

Figure 2. (a.) YSZ sensor, (b.) WBO sensor in enclosure, (c.) Complete testing and data processing system.

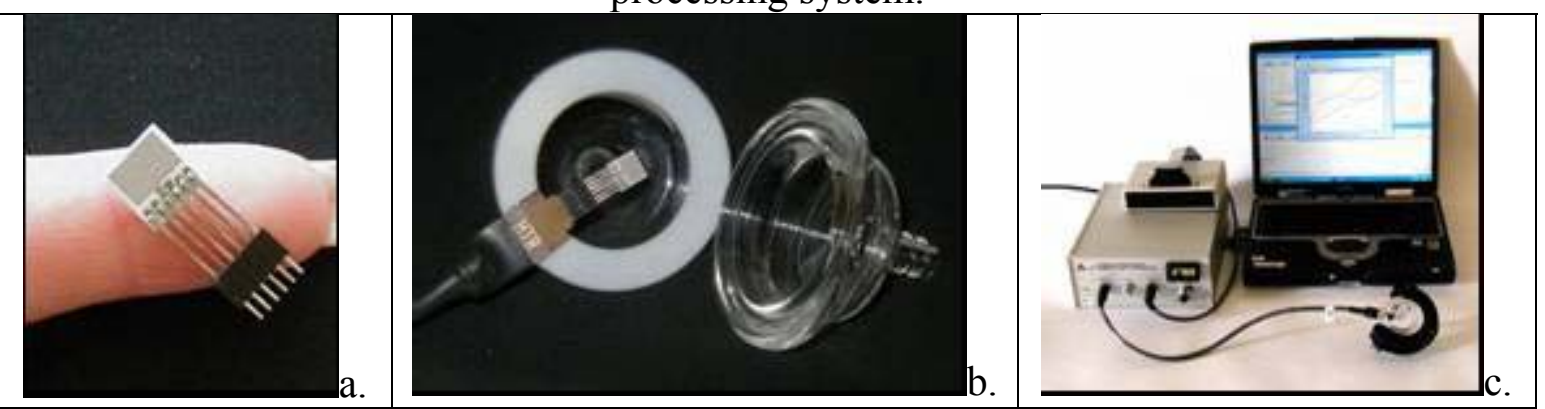

Gases, procured from AGA ${ }^{\mathrm{TM}}$, were used to test the sensor responses. The gases and concentrations are given in Table 2.

Table 2. Concentrations of Stock Gases Received

\begin{tabular}{|l|l|}
\hline Gas & Concentration \\
\hline Trichloroethylene, Balance air & $1002 \mathrm{ppmv}$ \\
\hline Tetrachloroethylene, balance air & $1002 \mathrm{ppmv}$ \\
\hline Acetone, balance air & $2501 \mathrm{ppmv}$ \\
\hline Acetophenone, balance air & $21.8 \mathrm{ppmv}$ \\
\hline
\end{tabular}


The stock concentration of acetophenone is less than requested. AGA indicated that a concentration of greater than $1000 \mathrm{ppm}$ was not attainable and stable.

Sensors were tested initially for their responsiveness to the gases using the undiluted stock gases. Sensors were enclosed in a glass container. Gases from the stock cylinders were directed into flowmeters. Gas from the flowmeter was directed into a Teflon mixing chamber where it was split. Half of the gas $(0.50 \mathrm{~mL} / \mathrm{min})$ was sent into a glass chamber housing the YSZ sensor; the other half $(0.50 \mathrm{~mL} / \mathrm{min})$ flowed through another glass chamber housing the WBO sensor. After chamber flushing, sensor readings were taken with the appropriate gases and recorded. Gases that were at lower concentrations that the stock gases were prepared using zero chromatographic air as the diluent and flowmeters to control the rate into the mixing chamber.

\section{The Results}

Sensors were fabricated using thick film screening techniques. The sensor base consisted of an aluminum oxide substrate. A platinum heating element was screened on the back side of the $\mathrm{Al}_{2} \mathrm{O}_{3}$ base and fired at $1300^{\circ} \mathrm{C}$. The $\mathrm{Al}_{2} \mathrm{O}_{3}$ plate was reversed and platinum electrodes were screened on the front. Again, the plate was sintered at $1300^{\circ} \mathrm{C}$. A layer of nickel oxide was screened on top of the electrodes, fired; a layer of platinum was screen on the base then fired; a layer of tungsten bismuth oxide was screened and the sensor fired; and a layer of platinum was screened over all other layers on the sensor and fired. This initial composition was tested to look at its reactivity toward the compounds selected. Trial tests showed that the YSZ sensor exhibited reactivity toward acetone and acetophenone; tests also showed that the WBO sensor exhibited reactivity toward the chlorinated compounds. Sensors were connected with leads to a data acquisition system, and the sensors were arranged in arrays so that they were exposed to the same gas together.

Stock gases were passed through flowmeters into the glass sensor cells. Six sets of voltammograms were gathered for each gas and recorded. Air (from a cylinder) containing less than $10 \mathrm{ppm}$ water was run as the standard background voltammograms. The collected voltammograms were compared to the background air voltammograms and compared to each other to determine where in the voltammogram chemical reactivity occurred. Chemical composition of the analytes were also extracted from the voltammograms using general regression neural networks (GRNNs) to provide analog values. Signatures were resolved by pattern recognition software tools. The mixed analyte voltammograms were classified using well-accepted chemometrics pattern recognition algorithms including radial basis function neural networks (RBFNs), probabilistic neural networks (PNNs), and support vector machines (SVMs).

Figure 3 shows the response of the WBO and the YSZ sensor to TCE. The WBO sensor response to TCE is concentration-dependent. On the left hand side of the WBO curve, between voltages $-1.0 \mathrm{~V}$ to $-0.5 \mathrm{~V}$, the sensor responds linearly until the concentration reaches $500 \mathrm{ppm}$. At $1000 \mathrm{ppm}$, the sensor may be saturated as the response is slightly different than that of the $500 \mathrm{ppm}$ concentration. The initial air response of the WBO sensor is different than that of the air responses following the TCE testing. The WBO sensor was not conditioned prior to running tests; since it was a new sensor, the different responses between the initial air reading and the 
final readings are expected. The YSZ sensor response to TCE between $-1.0 \mathrm{~V}$ and $0.0 \mathrm{~V}$ is distinguishable. The YSZ sensor reacts uniquely to the various concentrations of TCE in an incremental manner. The only concentration that the YSZ sensor does not respond to incrementally is the $1000 \mathrm{ppm}$ concentration of TCE. The high concentration may have saturated receptive sites on the sensor surface. The initial response to air with the TCE sensor and the response to air after all concentrations of TCE were run are not identical. Again, this may be attributed to the lack of a conditioning step prior to using the new YSZ sensor.

Figure 3. WBO and YSZ sensor response to TCE
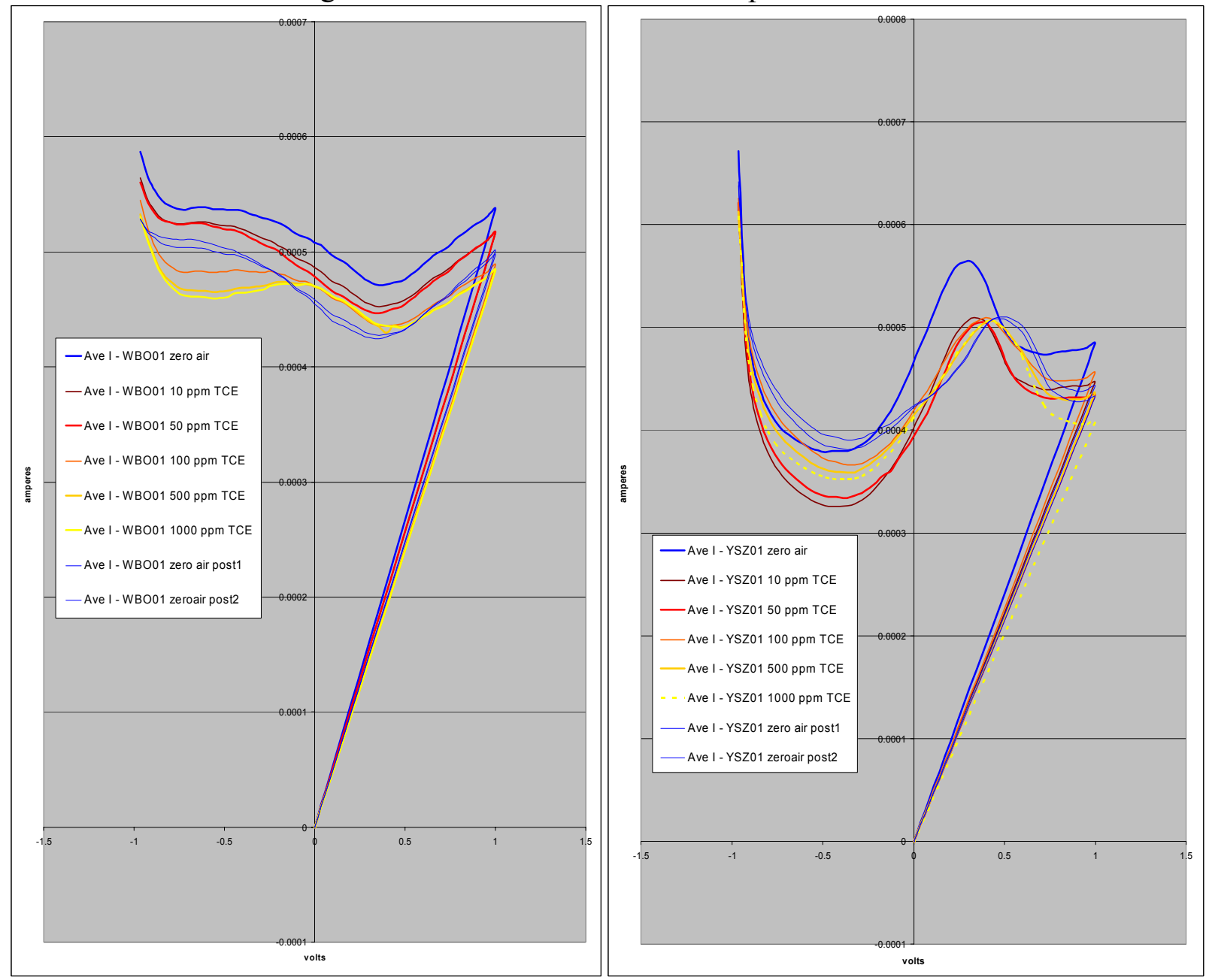

Figure 4 shows the response of a WBO sensor and an YSZ sensor to PCE. From $-1.0 \mathrm{~V}$ to +1.0 $\mathrm{V}$, the response of the WBO sensor is incremental and predictable. The response of the WBO sensor to $500 \mathrm{ppm}$ TCE and $1000 \mathrm{ppm}$ TCE is not very different (visually). Either the response is quadratic, or sites on the sensor are becoming saturated with PCE. The response of the PCE sensor to air is different for the air prior to running the PCE tests versus the readings after running the PCE tests. This is expected, as the sensor was not conditioned prior to running any tests. The YSZ sensor's response to PCE is predictable in the $-1.0 \mathrm{~V}$ to $-0.5 \mathrm{~V}$ range. The YSZ sensor's response to $500 \mathrm{ppm}$ and $1000 \mathrm{ppm}$ PCE is inconsistent with the response to the lower concentrations. This may be due to site saturation on the YSZ sensor surface. 
Figure 4. WBO and YSZ response to PCE.
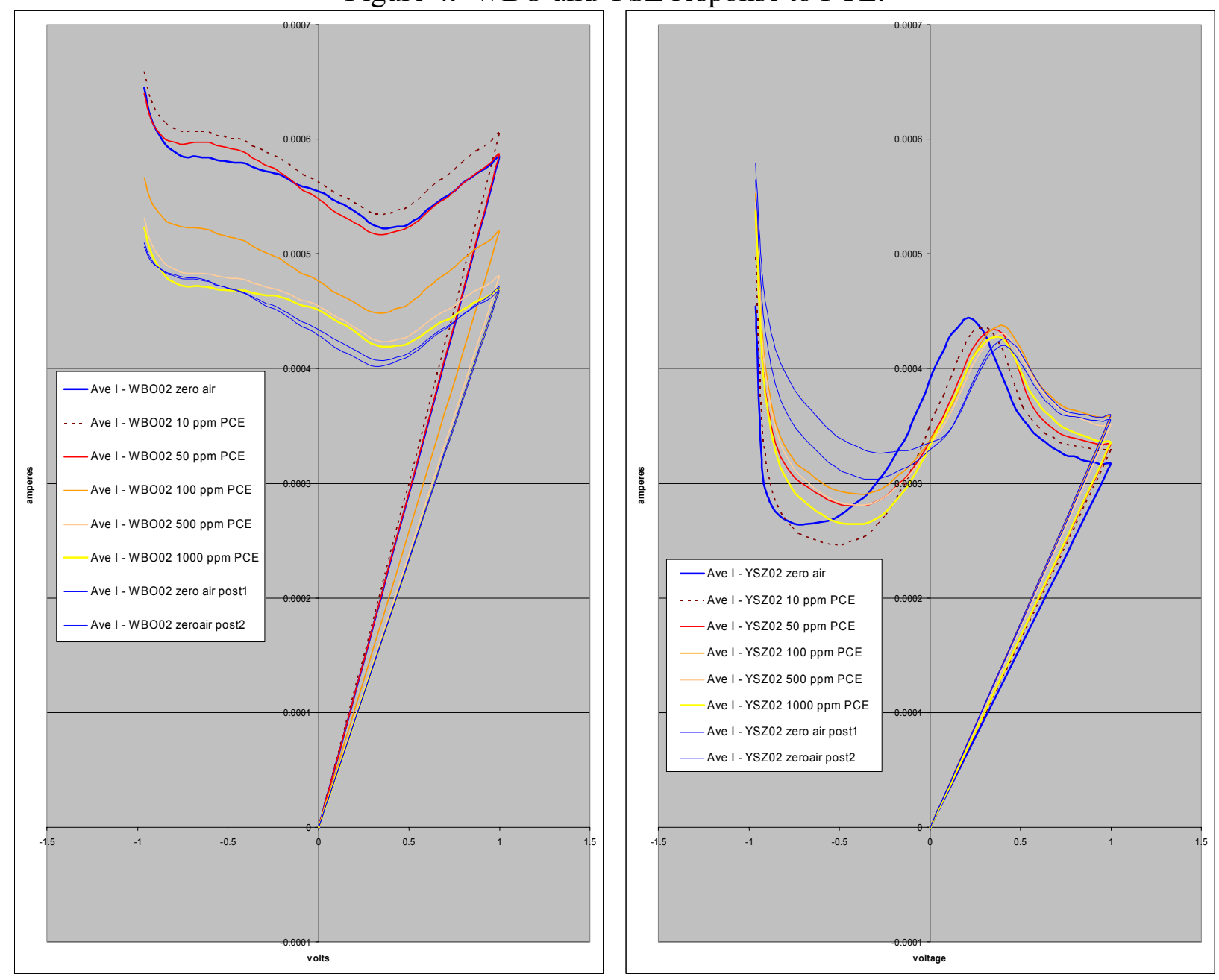

Figure 5 shows the WBO sensor response and the YSZ sensor response to gaseous acetone. For the WBO sensor, the response is extremely good; the concentrations are segregated from $50 \mathrm{ppm}$ acetone through $2500 \mathrm{ppm}$ acetone. The air response is unique. Although the initial air and final air responses are not exactly the same, this probably can be attributed to the lack of initial conditioning of the WBO sensor. The results from the YSZ sensor are equally good; all five concentrations of acetone produce unique voltammetric signals, and the signals are distinguishable. YSZ sensor recovery based on air response was not complete; again, this is probably due to lack of sensor conditioning. 
Figure 5. WBO and YSZ response to acetone
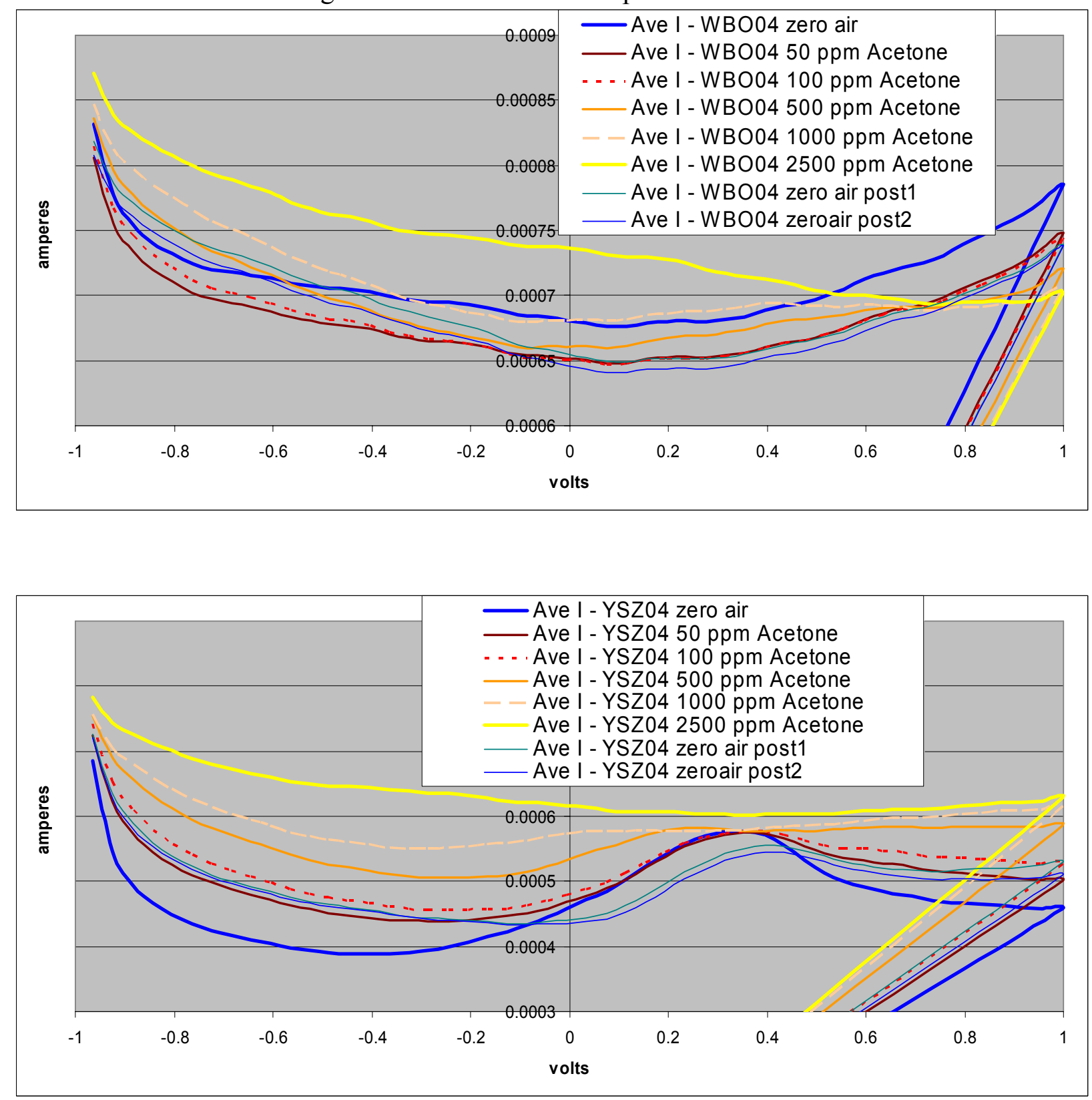

Figure 6 shows the results of the WBO and the YSZ sensor with gaseous acetophenone. Acetophenone concentrations ranged from $0.5 \mathrm{ppm}$ to $21 \mathrm{ppm}$ in a balance of air. The results for the WBO sensor are excellent. Acetophenone concentrations are resolved until they $21 \mathrm{ppm}$, where it appears that the sensor sites saturate and the voltammogram produced is the same as it was at $10 \mathrm{ppm}$. The recovery of air is not very good, probably because the sensor was not conditioned prior to use. The resolution of the voltammograms with the YSZ sensor is not as good as the results from the WBO sensor. Peaks for various concentrations are not wellseparated at any given voltage. 
Figure 6. WBO and YSZ response to acetophenone.
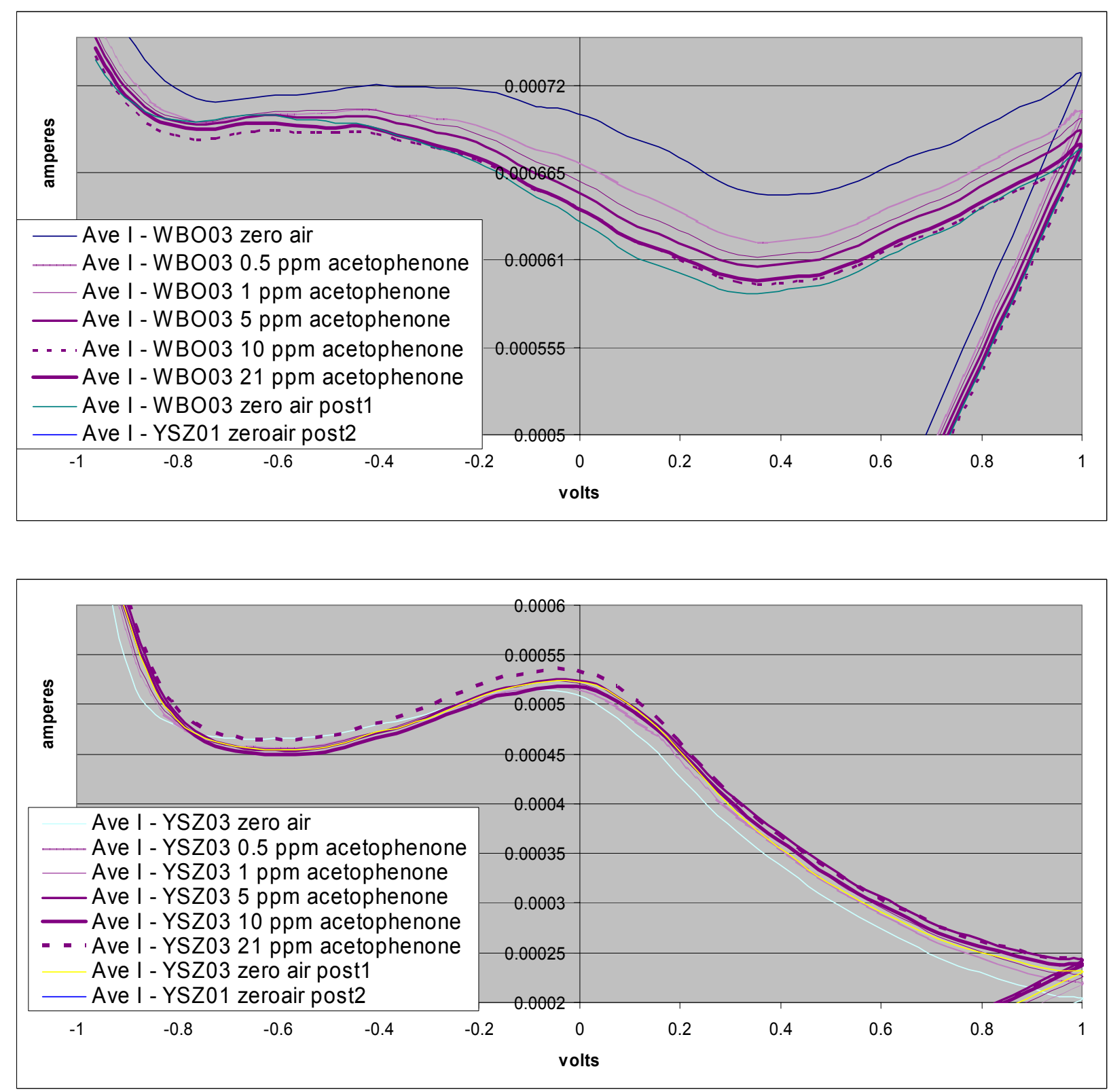

Figure 7 shows a select group of results from the tests using additive concentrations. All results are not presented in this graph because visually, it is too complicated to resolve. Pattern recognition tools are more effective at separating the data and phenomena. The WBO sensor used in these tests had been conditioned; this is evident in the air voltammograms and the improvement in background air response after the chemical tests had been run. In general, the voltammograms produced are unique. TCE and acetone produce a similar response as acetone alone does. However, this is resolved in the YSZ sensor voltammograms. 
Figure 7. WBO and YSZ response to mixtures of TCE, PCE, acetone, and acetophenone

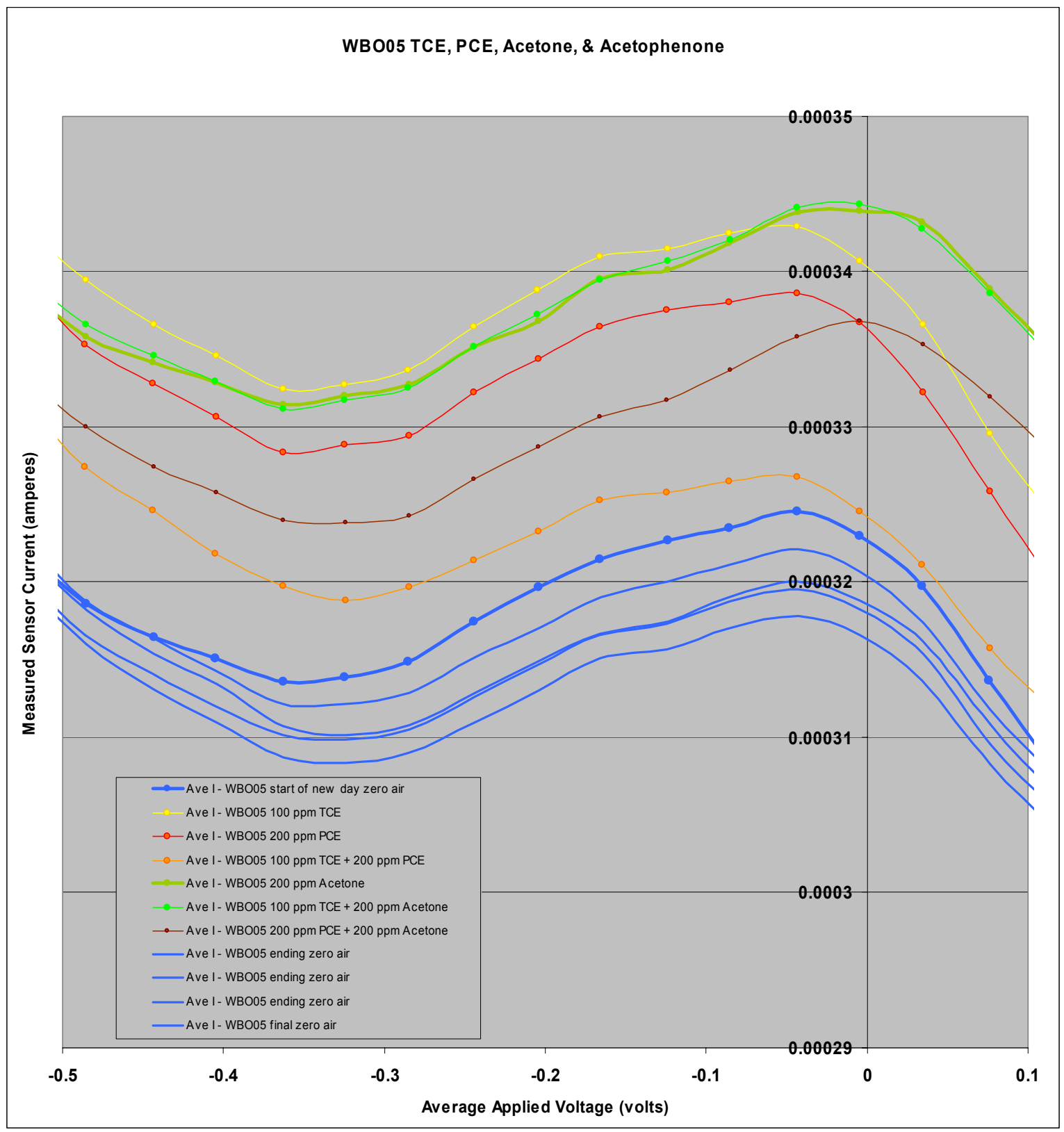




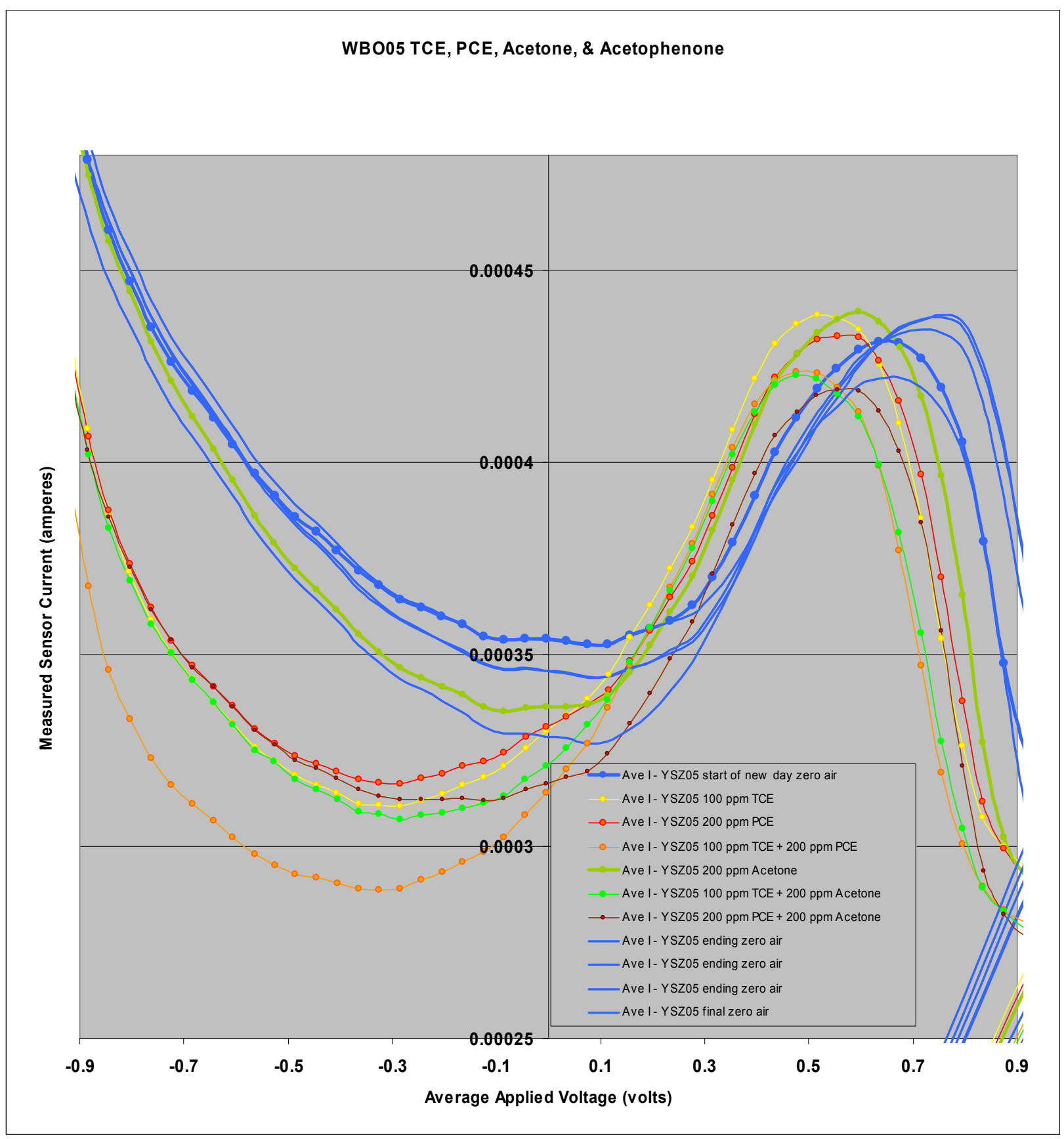

The final experimental task had focused on detecting specific chemicals in the headspace above a spiked sample of water. Figure 8 and Figure 9 show the results from tests that focused on the volatilization of TCE and acetone from aqueous solutions. In Figure 8, the results from TCE are shown with a WBO sensor and an YSZ sensor. Visual resolution of the TCE in the headspace is better with the YSZ sensor than it is with the WBO sensor. Concentrations are distinguishable. The air recovery with the YSZ sensor is not exceptional - this may be related to the lack of a conditioning step. 
Figure 8. WBO and YSZ response to TCE in the headspace above water
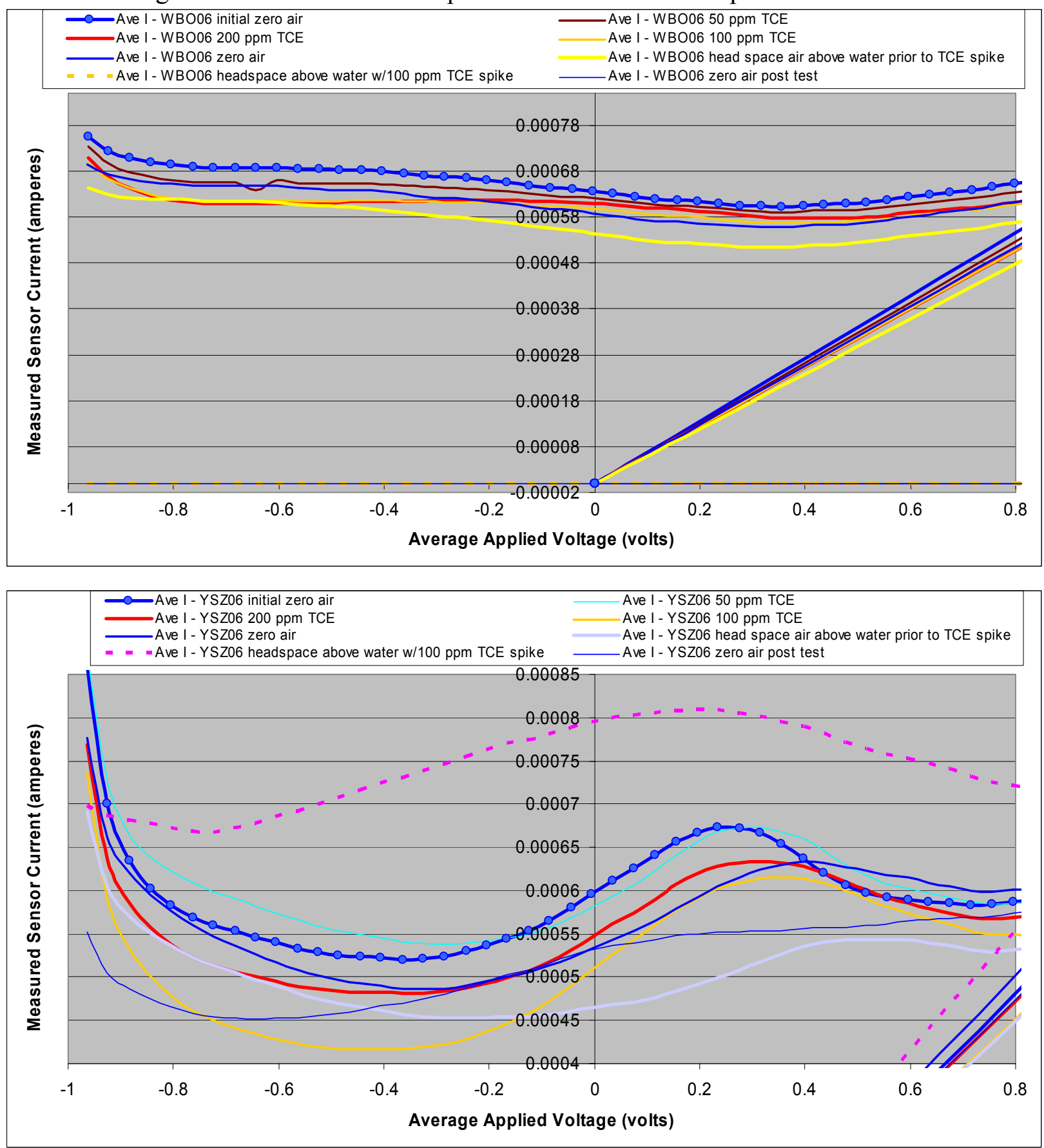

Figure 9 shows the results of a WBO and an YSZ sensor to detect acetone in the headspace above water. Responses from both sensors are superb; concentrations are visually distinguishable and incremental, suggesting that the sensor sites are not becoming saturated. At the end of the headspace analyses, gaseous acetone from a compressed cylinder was run (2501 ppm acetone). The voltammograms of the WBO sensor and the YSZ sensor show a more pronounced response with this concentration, which is expected. 
Figure 9. WBO and YSZ response to acetone in the headspace above water.
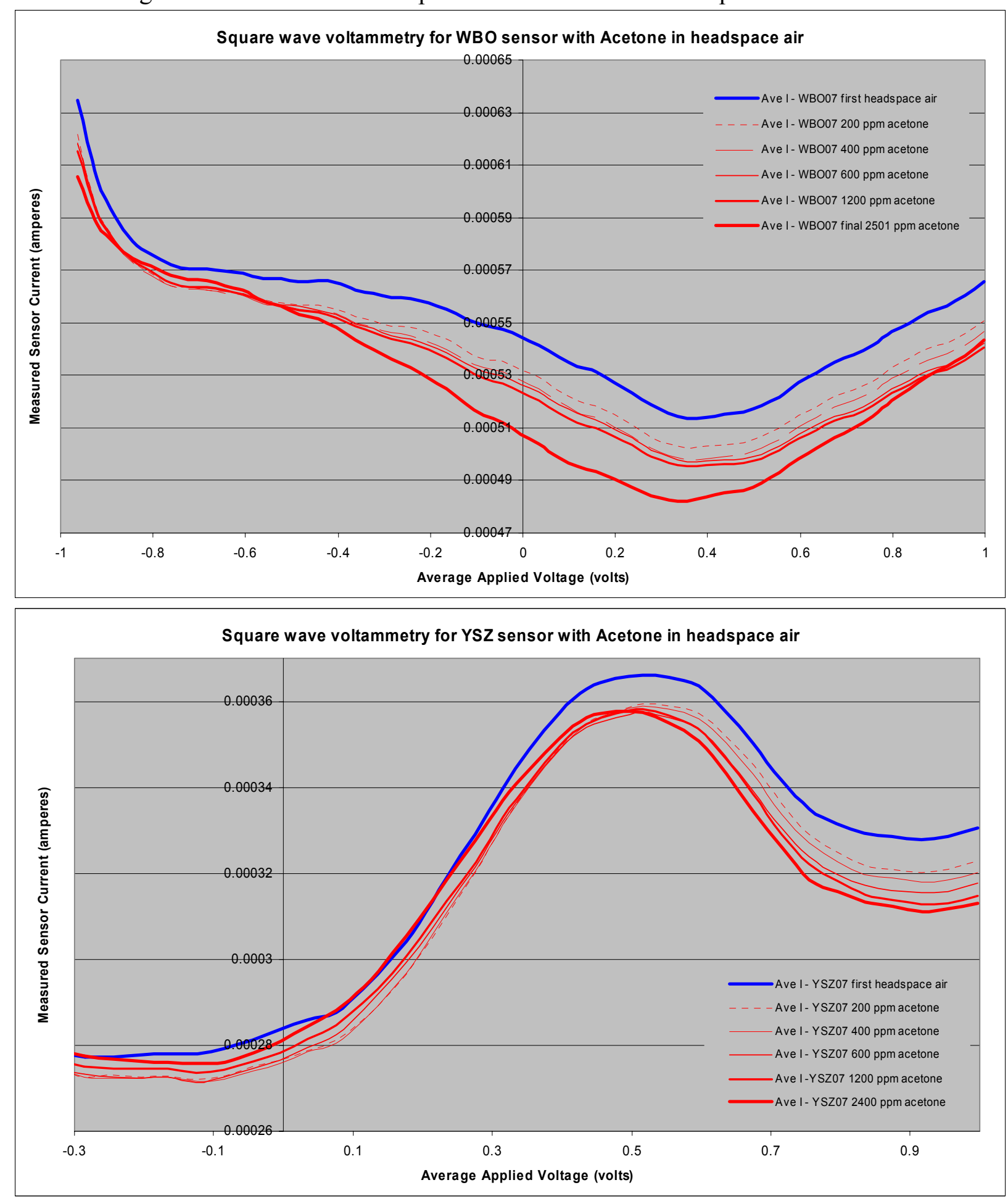

Overall, the WBO and YSZ sensors responded well to the chemicals in this study. Responses to various concentrations were distinguishable visually. This is a clear indication that pattern recognition tools will be effective in resolving the constituents and concentrations. In tests, such 
as the test with acetophenone, one sensor, the WBO sensor is not extremely effective. However, the other sensor, the YSZ sensor, is effective in resolving the concentrations. This supports the need to use an array of sensors, as one sensor may be reactive to a compound while another may not.

In the course of this research, several interesting phenomena surfaced. New sensors, that were fabricated but not used in a contaminant gas, seemed to function more effectively and predictably if a "conditioning" step was imposed upon them prior to use in square wave voltammetry. A conditioning step consists of running cyclic voltammetry prior to running square wave voltammetry. This step tends to "cleanse" the sensor surface by providing a full $1.0 \mathrm{~V}$ to $+1.0 \mathrm{~V}$ sweep and both oxidizing and reducing compounds on the sensor surface. [Note: squarewave voltammetry will simply oxidize or reduce compounds - it will not induce both reactions.] This sweep is essential for recovery between samples.

\section{Requirements for implementing gas voltammetry}

ALL of the information provided here is of an ANL-proprietary nature and is subject to licensing agreements. It is provided here for project planning and evaluation and its disclosure here does not imply freedom to use without negotiating a formal license.

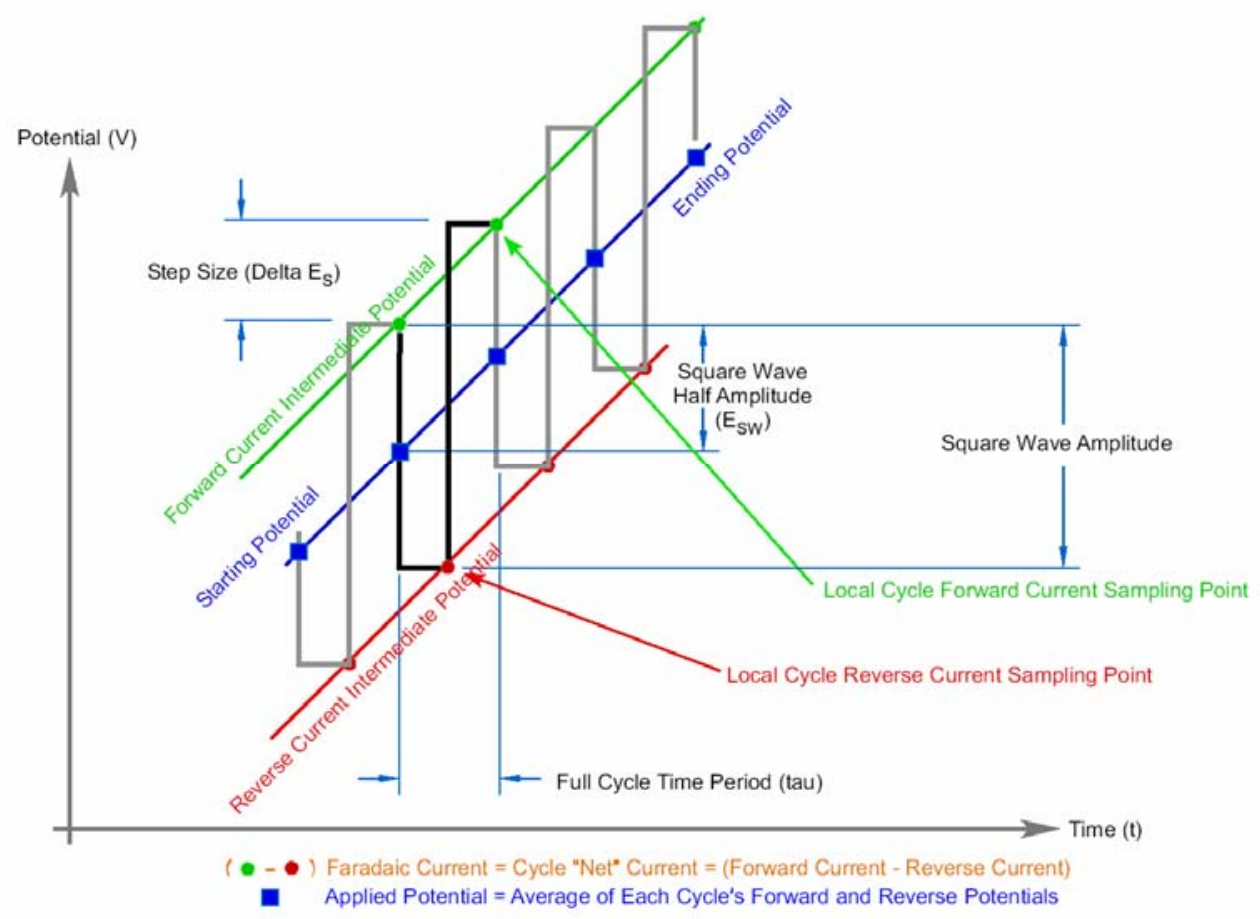

Square Wave excitation signal for voltammetry

There are two major ways to implement the voltammetry that ANL employed for the ANS gas testing. The simpler method only implements the voltammetry measurement, and stores the voltammogram for communicating to an external device or services for analyzing the signature. This simpler method only has to be able to generate the illustrated waveform, and perform A/D 
sampling as indicated. The more involved method implements both the voltammetry measurement and has the chemometrics algorithms on-board to process that signature and produce actionable information such as classification or numerical analysis. The memory and mathematics library required to perform the [neural network] chemometrics is not excessive, but is more common for micro computers and digital signal processors (DSPs) than for microcontrollers.

To implement two-electrode gas voltammetry the hardware needs to be able to digitally [numerically] control a single output potential, and two channels of input voltage measurements, with a 12-bit resolution. The output range should be bipolar and capable of +/- 2 VDC; though +/- 5 VDC would be more flexible and common. The outputs need to be controllable to generate both a simple stair-step output, and a square wave superimposed on the stair-step as shown above. Both waveforms are used for operation. The rates of change of this output potential require (50) full square wave cycles in $\sim 0.25$ seconds, though much of the classical analysis performed operated at a significantly slower rate of (50) cycles in 20 seconds. The A/D capability must allow for two channels of +/- 5 VDC inputs. ANL has an instrument amplifier schematic for implementing a "potentiostat" interface between any data acquisition hardware and the sensing elements.

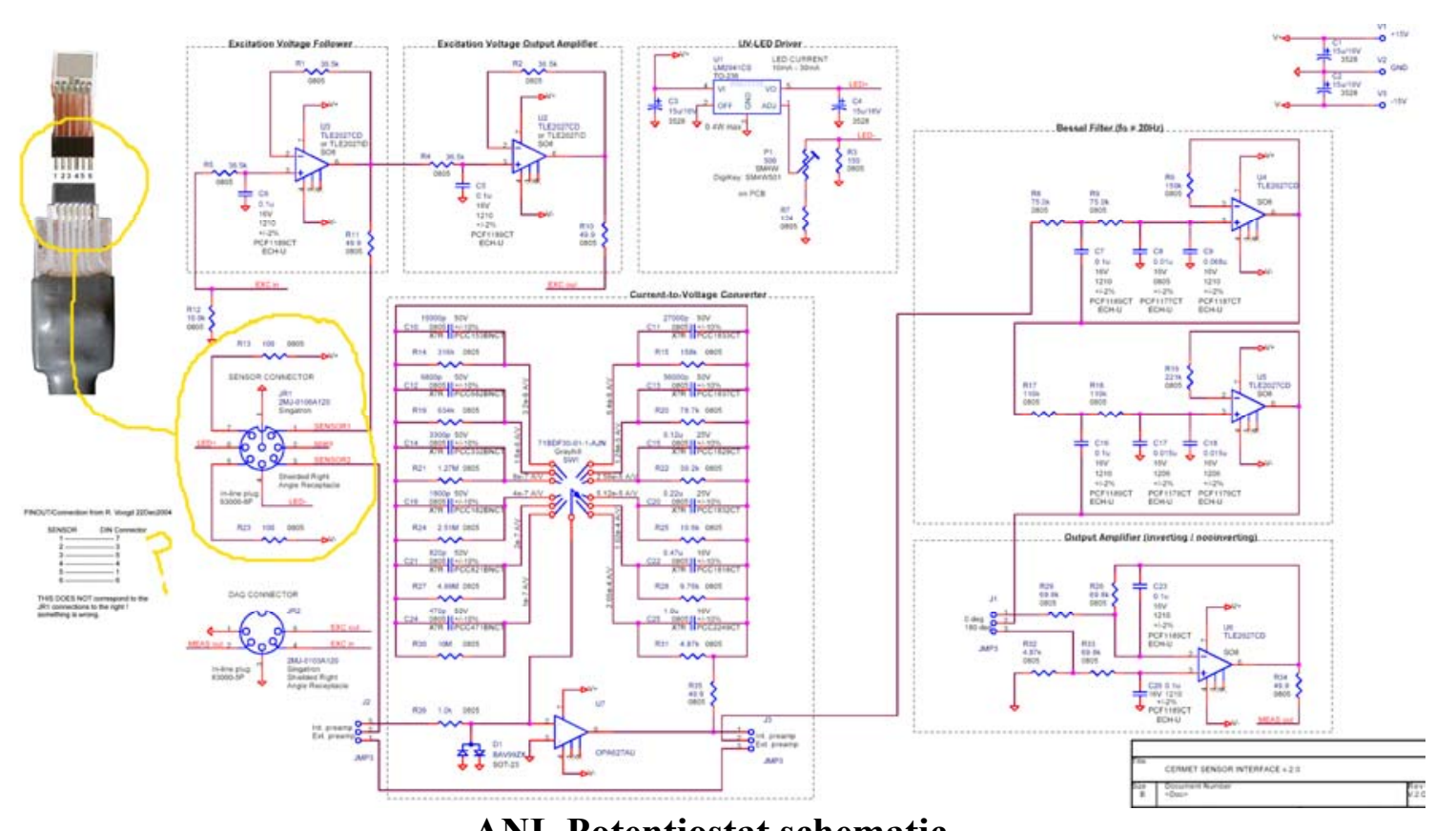

ANL Potentiostat schematic 


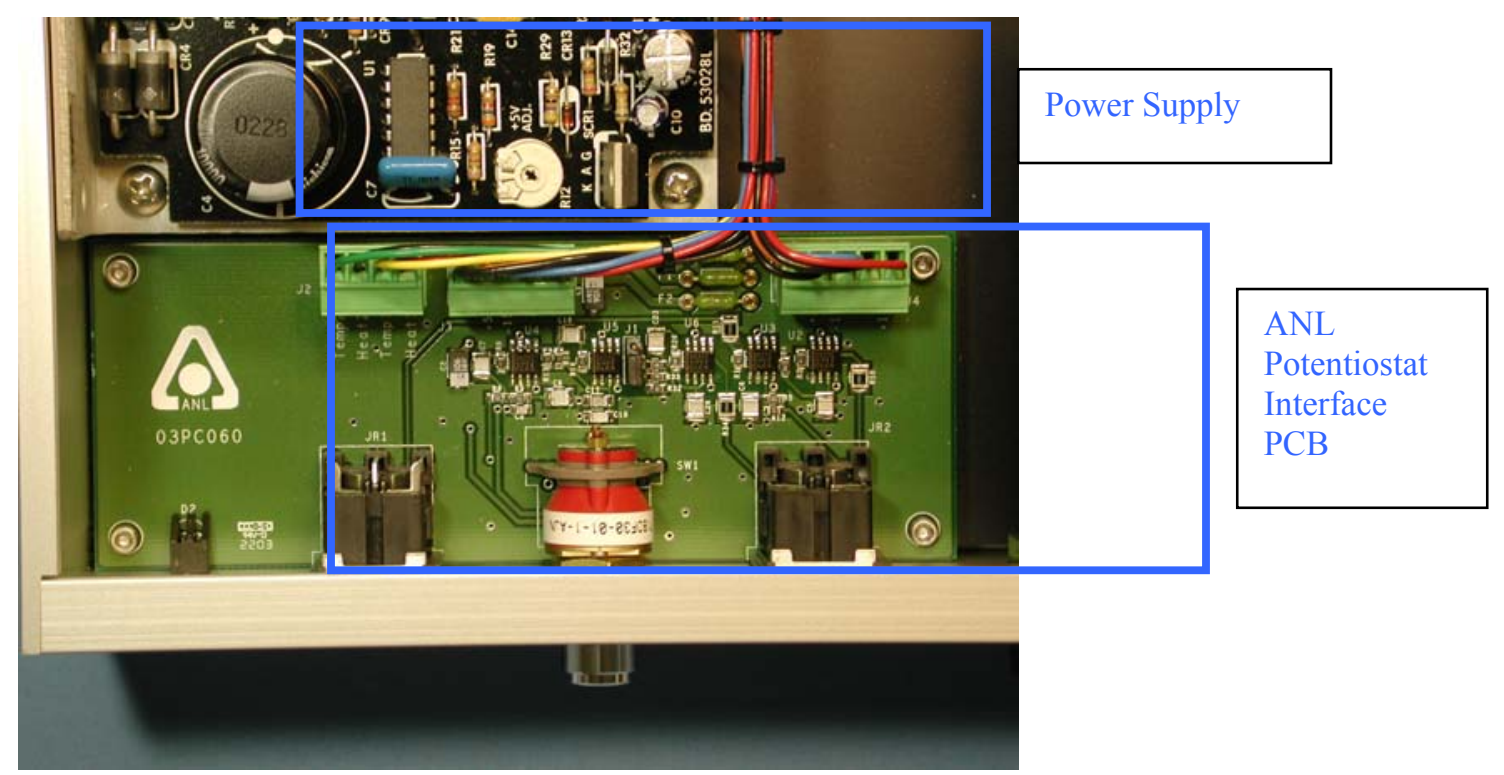

ANL Potentiostat Printed Circuit Board

One of the A/D channels will be sampled to verify the applied potential, while the other A/D channel will be sampled to measure the electronic current associated with the voltammetric measurement. The measured potential (voltage) will be inspected for correctness, and then discarded. The measured current will be processed as the chemical signature.

If the signature is to be communicated to some external devices for processing, it is a simple matter of sending (50) 12-bit measurements in a packet, along with various meta-data describing where it came from. Many sensors and voltammetry sources can be operated from one management host polling them at whatever rate suits a given problem or application.

The device needed to analyze the signatures must be capable of executing simple instructions. The typical classification strategy requires the ability to compare the 50-measurement signature vector to other vectors with the same structure. This can be done my calculating the Cartesian distance between the vectors. Any decent mid-range microcontroller has this capability, and the ability to store as many of these $50 \times 12$-bit example signatures as is dictated by a problem. The math libraries needed must allow for simple algebra,,.,$-+-{ }^{*}$, and storage of intermediate sums and products. If the ability to learn new signatures is required, than additional math capability is also required, but is not excessive - only doubling the storage space otherwise needed to analyze the signatures.

ANL has implemented examples of these routines on $\$ 2$ microcontrollers with 8-bit data busses and 14-bit instruction sets using only 24-bit math routines, and even scaled integer math routines. 


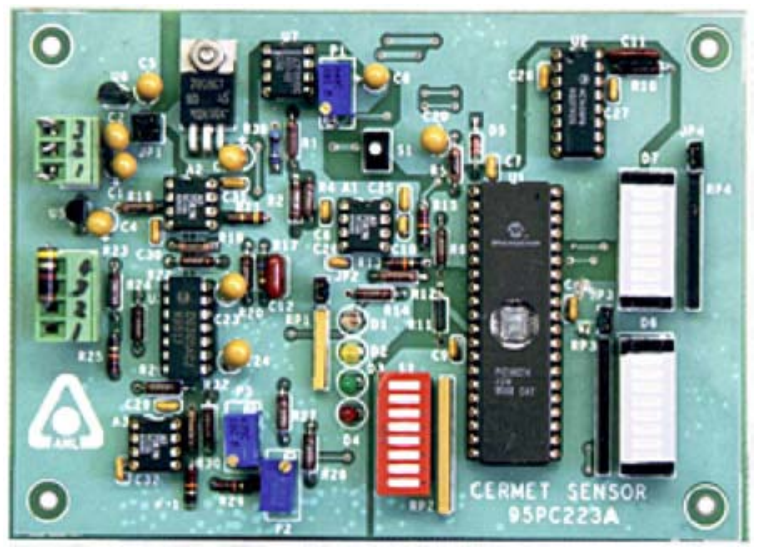

ANL Generation 1 microcontroller-based potentiostat circa 1996

The neural signature processing can be scaled to the hardware. ANL typically completes all of its R\&D software and algorithm engineering on a notebook computer, running Windows XP and MathWorks MATLAB software, with National Instruments DAQCard 6024/6064E series hardware.

The final remaining portion of the required hardware is a circuit to control the temperature of the sensing element or array. This is very problem-specific, but can follow several generalized forms. Schematics are shown below.

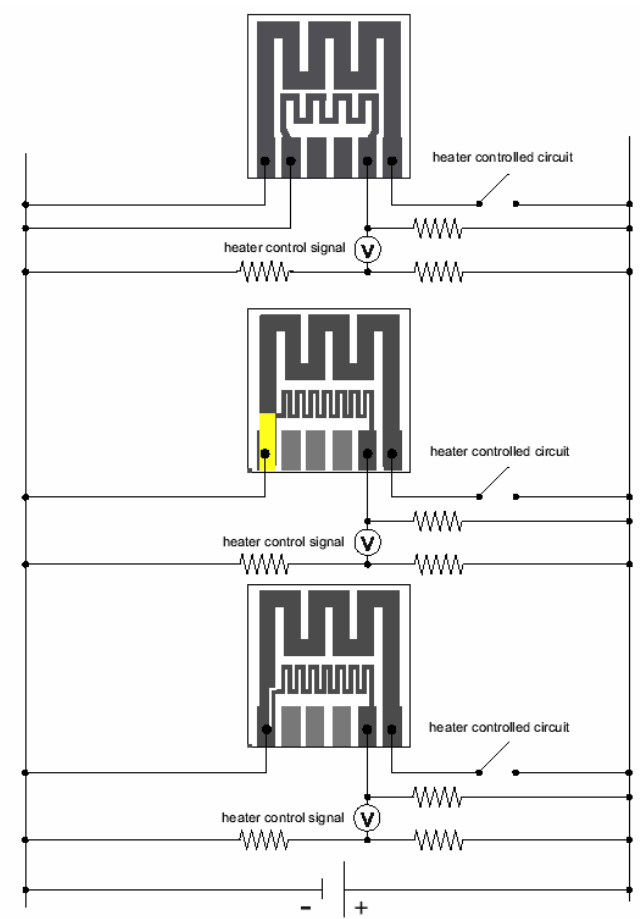

Heater Power

Three heater-control options. 4-lead heater/RTD, 3-lead heater/RTD option 1, 3-lead heater/RTD option 2. 
The ANL palm-sized devices used a pulse-width-modulated (PWM) oscillating heating signal and controlled the medium sized sensor arrays to $+/-1^{\circ} \mathrm{C}$, which was fine for evaluation purposes.

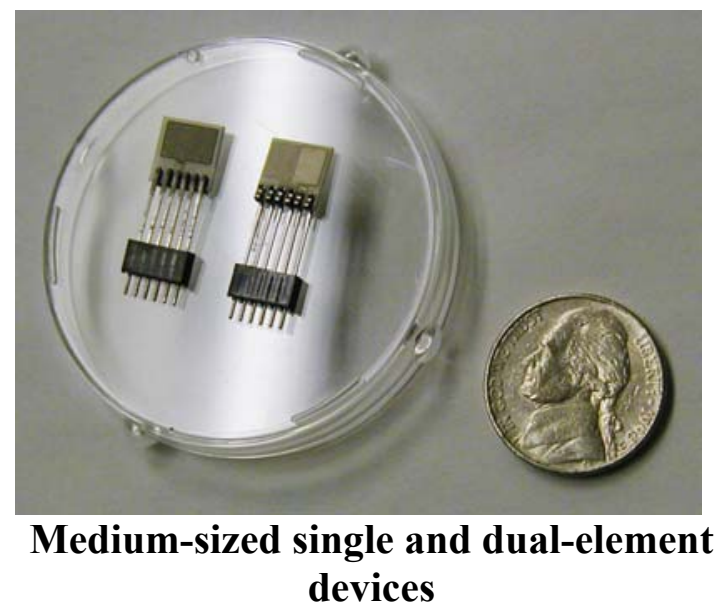

This approach did not have the finesse for the smaller $2 \mathrm{~mm} \times 4 \mathrm{~mm}$ devices and so a new commercial-off-the-shelf (COTS) temperature controller was included in the lab instruments. These devices were common Omega brand PID-type controllers and interfaced to the heater/RTD (temperature probe) through a small buffering amplifier to match impedances. The commercial controllers expect either a platinum resistance thermometer (PRT) with a typical 100 $\Omega$ resistance, or a thermocouple. The ANL microsensors had a PRT, but its nominal resistance was closer to $10 \Omega$. The use of these devices provided finer control resolution that was needed for most applications, better than $+/-0.1^{\circ} \mathrm{C}$ control, but were helpful to have for validating an experimental detection technology. Regardless of controller, the three circuits shown are still viable for where to install that controller. If the size of the device is not critical (which means also that the power to heat the device is not critical) then the separated 4-lead heater/RTD is simpler to interface to and therefore has an advantage of robustness, but also requires an additional pin.

\section{References}

Barnoski, M.K, S. M. Jensen, Appl. Optics, 15 (1976) 2112

Grate, J., S. Martin, R. White, Anal. Chem. 65 (1993) 940A.

Heineman, W.R., C.J. Seliskar, J. Richardson, Aust. J. Chem., 56 (2003) 93.

Kano, H. S. Kawata, Appl. Optics, 33 (1994) 5166.

Rogers, A.J., Phys Reports, 169 (1988) 99.

Schwarzenbach, R.P., P. M. Gschwend, and D.M. Imboden, Environmental Organic Chemistry, John Wiley and Sons, Inc., New York, 1993, p.110.

Shoemaker, E. L., M. C. Vogt, F. J. Dudek, Solid State Ionics, 92 (1996), 285.

Shoemaker, E. L., M. C. Vogt, F. J. Dudek, T. Turner, Sensors and Actuators A: Physical, 42 (1997) 1.

Skubal, L.R., N.K. Meshkov, and M.C. Vogt, J. Photochem. \& Photobiol. A: Chemistry, 148, (2002) 103.

Vogt, M. C., E. L. Shoemaker, D. A. MacShane, T. Turner, 36 (1997) 370. 
Vogt, M. C., E. L. Shoemaker, D. A. MacShane, T. Turner, SENSORS Journal of Applied Sensing Technology (1996) 54.

Vogt, M.C., L.R. Skubal, Environmental Monitoring and Remediation Technologies, Tuan VoDinh, Robert L. Spellicy, Editors, Proceedings of SPIE, 3534 (1998) 412 


\section{Resumes}

\section{EDWARD G. GATLIFF, Ph.D.}

Position: $\quad$ President, Applied Natural Sciences, Inc.

Education: Ph.D., Soil Fertility/Chemistry, University of Nebraska-Lincoln - 1985

B.S., Soil Management/Genesis, The Ohio State University - 1977

\section{PROFESSIONAL EXPERIENCE:}

Applied Natural Sciences, Inc. Hamilton, Ohio 1993-present, Founder and President

Responsible for development and implementation of patented TreeMediation ${ }^{\circledR}$ and TreeWell ${ }^{\circledR}$ technologies and related strategies for the cleanup of the environment using natural processes that include the remediation of the soil and groundwater at government, commercial and industrial facilities located in Ohio, Pennsylvania, Massachusetts, New York, New Jersey, Maryland, Michigan, Illinois, Wisconsin, Missouri, North Carolina, South Carolina, Georgia, Florida, Louisiana, Oklahoma, and Nevada and in Ontario and Alberta, Canada.

- "Root Engineering for Self-Irrigation that Exploits Soil Depth Dimension for Carbon Sequestration" (deep rooting technologies to increase carbon sequestration) - SBIR Research

- "Modular TreeMediation ${ }^{\circledR}$ Bioreactor System" (treatment of landfill lechate, and metal/organic-laden process and waste water) - Southeastern Technology Center Research

- "Picatinny Arsenal Pb and As Phytoremediation Studies" (Uptake and attenuation of lead and arsenic in poplar and willow trees) - SBIR Research

\section{RELEVANT PUBLICATIONS:}

- $\quad$ "Say It With Trees", October, 1993, Soils, Group III Communications, Inc., Publishers

- "Innovative Vegetative Remediation Process Using Trees Offers Advantages Over Traditional Pump and Treat Technologies", May, 1994, Remediation Journal, Executive Enterprises, Publishers, Volume 4, No. 3.

- Nyer, E.K. and E.G.Gatliff. 1996. Phytoremediation. Ground Water Monitoring and Remediation 16(1):58-62

- $\quad$ Quinn, J.J., M.C. Negri, R.R. Hinchman, L.P. Moos, J.B. Wozniak and E.G. Gatliff. 2000. Predicting the Effect of Deep-Rooted Hybrid Poplars on the Groundwater Flow System at a Large-Scale Phytoremediation Site. International Journal of Phytoremediation

- Quinn, J.J., E.G. Gatliff, J. Baker, M. C. Negri, L. Moos, J. Kupar, 2002, Phytoremedial Solutions for Deep Groundwater: National Ground Water Association 2002 Midwest Focus Ground Water Conference, Chicago, April 11-12, Abstracts p. 50.

- Zellmer, S.D., R.R. Hinchman, M.C. Negri, J.F. Schneider, and E.G. Gatliff, 1997. Using Phytoremediation to Clean Up Contamination at Military Installations, Second Tri-Service Environmental Technology Workshop, St. Louis, Mo., June 10-12.

\section{BOOK CHAPTERS:}

Negri, M. C., E.G. Gatliff, J. Quinn, and R.R. Hinchman. Below Ground Exchange Surface: Root Growth, Plume Interception and Contaminant Uptake as a Function of Contaminant Depth and Site Stratigraphy. In: Phytoremediation: Transformation and Control of Contaminants, McCutcheon S. C. and J. L. Schnoor, Editors, John Wiley and Sons, Inc. In press. 


\section{Laura Rachel SKubal, Ph.D.}

Argonne National Laboratory, Energy Systems Division

9700 South Cass Avenue, Argonne, IL USA 60439-4815
Phone: (630)252-0931

E-mail: 1skubal@anl.gov

\section{Education}

Ph.D.

M.S.

Environmental Engineering Pennsylvania State University, State College, PA

B.S.

Environmental Engineering

University of Illinois, Champaign, IL

Environmental Engineering

Northwestern University, Evanston, IL

\section{Professional Experience}

1996-present Argonne National Laboratory, Argonne, IL, Environmental Engineer

1986-1996 Argonne National Laboratory, Argonne, IL, Analytical Chemist

1995-1996 The Pennsylvania State University, State College, PA, Adjunct Quality Control/Quality Assurance Manager

1991-1992 Northwestern University, Evanston, IL, Adjunct Research Assistant

\section{Research Experience}

- Co-principal investigator on DoD-funded SERDP project "The Development of Spatially-Based Emission Factors from Real-Time Measurements of Gaseous Pollutants Using Cermet Sensors," for the development of microsensors to detect exhaust emissions.

- Served as a principal investigator on projects to develop sensors for detecting chemical agents, aqueous metals, and groundwater contaminants such as TCE and PCE.

- Investigated the use of colloidal titanium dioxide photocatalysts for removal of organic gaseous constituents, soluble metals, and recalcitrant organics from industrial waste streams.

- Investigated, quantified, and modeled the chemical impact on soil and water quality of natural gas pipeline dredging, installation, and backfill operations.

- Performed site characterizations and bench-scale tests to design decontamination, stabilization, and immobilization strategies for metals and organics in soils.

- Assessed erosion control and revegetation techniques on military parachute drop zones.

\section{Select Publications and Awards}

Skubal, L.R. and N.K. Meshkov, "Reduction and Removal of Mercury form Water Using Arginine-Modified $\mathrm{TiO}_{2}$," Journal of Photochemistry \& Photobiology A: Chemistry, 148 (2002) 211-214.

Skubal, L.R., N.K. Meshkov, T. Rajh, and M.C. Thurnauer, "Cadmium Removal from Water Using Thiolactic Acid-Modified Titanium Dioxide Nanoparticles," Journal of Photochemistry \& Photobiology A: Chemistry, 148 (2002) 393-397.

Skubal, L.R., N.K. Meshkov, and M.C. Vogt, "Detection and Identification of Gaseous Organics Using a $\mathrm{TiO}_{2}$ Sensor," Journal of Photochemistry \& Photobiology A: Chemistry, 148 (2002) 103-108.

R\&D 100 Award 2002, Smart Sensor Developer Kit, M.C. Vogt, L.R. Skubal, E. Shoemaker, (Argonne National Laboratory), J. Ziegler (General Atomics). 


\section{MICHAEL CHARLES VOGT, Ph.D.}

\author{
Computer Scientist/Research Engineer \\ Energy Systems Division (ES) \\ Argonne National Laboratory (ANL)
}

\author{
Contact Information \\ Phone: 952/884-7234 home office \\ 630/252-7474 lab office \\ e-mail:vogt@anl.gov
}

\section{Educational Background}

Ph.D. $\quad$ Computer Science, Illinois Institute of Technology, IL

M.S. Computer Science, Illinois Institute of Technology, IL

B.S. $\quad$ Engineering Physics, Bemidji State University, MN

Professional Experience

Mar1988-Present Principal Investigator, Chemical Microsensors Program

Energy Systems Division

Argonne National Laboratory

As project manager and principle investigator for the ANL Chemical Microsensors Program, I designed, planned, and developed a series of intelligent chemical sensors (mini, micro, and array) and chemical measurement technologies including complex hybrid microelectronics and computer hardware/software. I have taken this sensor program through conception to full military field demonstration and commercial fabrication. I have developed a very strong capability in pattern recognition techniques both in software and in hardware. The chemometrics algorithms I had developed I formalized into an approach for sensor signal processing called Sensometrics. Sensometrics is realized as a larger data mining, sensor signal processing, and expert system, the Sensor Algorithm Generation Environment (SAGE) which was part of my Ph.D. dissertation topic. As a member of a larger team, I have combined my chemical detection, GIS, engineering, and expert systems backgrounds, to design emergency management systems for international utilities industries. This system has allowed me to update my existing background in (wireless) data communication technologies in support of SCADA systems and applied expert systems that also would support my research in developing detection/monitoring networks for chemical sensors. The sensor technology has produced several patented multiple gas microsensors, microsensor arrays, and electronic systems being adopted by the US Navy defense systems.

\section{Honors and Select Publications}

R\&D Magazine's International R\&D100 Award for 100 most significant new technologies. "Smart Sensor Developers Kit", 2002Laboratory Director's Outstanding Performance Award - Argonne National Laboratory, 2001

Fraden, Jacob, and M. Vogt, 2003, "Chemical Sensors" in Handbook of Modern Sensors, $3^{\text {rd }}$ Ed., American Institute of Physics, Woodbury, NY.

Vogt, Michael C., J. Ziegler, J. Wong, and F.W. Williams, 2000, Smart Microsensor Arrays For DC-ARM: Data Analysis Report for Fire Testing on ex-USS Shadwell, U.S. Naval Research Laboratory

Vogt, Michael. C., US Patent \#6,484,133 Issued November 2002, Sensor Response Rate Accelerator

Vogt, M. C., E. L. Shoemaker, A.V. Fraioli, US Patent \#5,429,727 Issued July 1995, Electrocatalytic Cermet Gas Detector/Sensor 